\title{
A APRESENTAÇÃO DE SI EM NARRATIVAS AUTOBIOGRÁFICAS DE ADULTOS COM BAIXAS QUALIFICAÇÕES ESCOLARES
}

\author{
(The presentation of the self in adults autobiographical narratives with low educational \\ qualifications)
}

\author{
António Calha ${ }^{1}$ \\ (Universidade de Lisboa)
}

\begin{abstract}
RESUMO
Neste artigo analisamos o discurso autobiográfico de adultos pouco escolarizados, centrando-nos na forma como se apresentam e justificam o seu modo de ser. O nosso objetivo é identificar os recursos reflexivos que dão conteúdo à autoidentidade e a forma como esta varia social e culturalmente em função da variação das estórias que compõem a história pessoal. Face ao nosso objetivo, recorremos a um conjunto de cem documentos autobiográficos elaborados em processos de Reconhecimento, Validação e Certificação de Competências entre 2006 e 2012. Na análise realizada foram identificados dois modos distintos, ainda que complementares, de apresentação de si. Um primeiro modo corresponde à descrição da forma como o sujeito se tornou ele próprio, realçando as experiências de infância que moldaram o caráter individual. $O$ segundo modo narrativo corresponde à descrição de aprendizagens que decorrem dos diferentes papéis sociais assumidos, destacando-se a forma como as diferenças de género se repercutem na argumentação.
\end{abstract}

Palavras-chave: Self, identidade, autobiografia.

\begin{abstract}
In this article we analyze the autobiographical speech of adults with low educational qualifications focusing on the way they justify their self. Our goal is to identify the reflective features that give content to the selfidentity and how it is modified by the variation of the stories that build up the personal story. For this purpose, we used an analytic corpus constituted by one hundred autobiographical documents written on Portuguese Accreditation of Prior Experiential Learning System between 2006 and 2012. The results revealed two different ways of presenting the self. A first mode corresponds to the description of how the subject has become himself highlighting the childhood experiences that shaped the individual character. The second narrative mode corresponds to the description of learning trough the different social roles assumed, highlighting how gender differences are reflected in the arguments.
\end{abstract}

Keywords: Self, identity, autobiography.

Recebido em: julho 2018

Aceito em: dezembro 2018

DOI: $10.26512 /$ les.v20i1.10784

\footnotetext{
${ }^{1}$ Prof. Adjunto do Instituto Politécnico de Portalegre; Doutorado em Sociologia pelo Instituto de Ciências Sociais da Universidade de Lisboa; Membro Integrado do Centro de Investigação para a Valorização de Recursos Endógenos VALORIZA. E-mail: antoniocalha@hotmail.com
} 


\section{INTRODUÇÃO}

O conceito de identidade tem sido objeto de ampla discussão nas ciências sociais dada a diversidade de prismas e perspetivas que o mesmo suscita. Ainda assim, é possível encontrar alguns elementos minimamente consensuais relativamente ao conceito de identidade (KAUFMANN, 2005: p. i). Em primeiro, lugar a identidade é o resultado de uma construção subjetiva que envolve o modo como os sujeitos se pensam a si e à realidade; ii) em segundo lugar, ela é influenciada por condições sociais que ultrapassam a vontade do sujeito. Esta característica dialética da identidade faz com que a permanente construção e reconstrução da identidade oscile entre a subjetividade e as condições objetivas que a influenciam. De tal modo que, como propõem Maheire (2002), se revele mais eficaz a utilização da designação "constituição do sujeito" ou "constituição da identidade" para descrever o processo de construção de si, diferente dos outros.

Várias das abordagens sobre o conceito de identidade (GERGEN, 1991; HALL, 1998; KAUFMANN, 2005) revelam-se críticas relativamente à ideia de unicidade identitária do indivíduo que o acompanha ao longo da sua existência. Gergen (1991), por exemplo, refere-se a uma multiplicidade de possibilidades de ser, algumas contraditórias, que derivam do aumento de oportunidades de relacionamento com os outros que as sociedades contemporâneas proporcionam. Como salientam Rasera, Guanaes e Japur (2004), Gergen descreve o self como um discurso influenciado pelo contexto histórico, quer através da permanente (re)criação de vocabulário sobre o self, quer pela disponibilização social de narrativas sobre o self. Desta forma, parece-nos claro que a identidade não pode ser perspetivada como um fenómeno estanque, ainda que pressuponha continuidade no tempo e no espaço.

A identidade é, portanto, um processo instável e inacabado e que não é imune à influência das particularidades do contexto socio-histórico. Ou, como formula Giddens (2002), cada indivíduo vive uma biografia reflexivamente organizada em termos do fluxo de informações sociais e psicológicas, e é nessa capacidade de manter em andamento uma narrativa biográfica particular que se encontra a identidade. Como refere o autor, a reflexividade pertence à historicidade reflexiva da modernidade, uma forma distinta do monitoramento reflexivo mais geral da ação. A regulação social e o determinismo institucional dos percursos individuais parecem ser colocados em causa de forma crescente, nas sociedades ocidentais, por um alargamento das possibilidades de escolha que se colocam aos indivíduos. Assim, a "biografia normal" tende a transformar-se numa "biografia faça-você-mesmo" (BECK; BECK-GERNSHEIM, 2002, p. 3). Este não é, necessariamente, um processo bem-sucedido, pois, como referem os autores, a "biografia faça-você-mesmo" é sempre uma biografia em risco. As biografias passam a ser alvo de intensa reflexividade e 
autodeterminação, gerando, consequentemente, um estado de permanente risco: tudo passa a ser da responsabilidade do indivíduo. A reflexividade do eu é contínua, e tudo abrange.

Este é o contexto em que, nos últimos anos, se tem redobrado o interesse pela narrativa autobiográfica enquanto meio de acesso à reflexividade individual que sustenta a identidade pessoal, ou seja, à dimensão interna e subjetiva do processo de construção da identidade. Como afirma Carvalho (2003), o autorrelato constitui um locus privilegiado do encontro entre a intimidade do indivíduo e a sua inscrição no contexto histórico e social. É no acesso que proporciona à privacidade do sujeito e à sua relação com o contexto social da sua existência que a narrativa autobiográfica desvenda as perceções, imaginações, reflexões e emoções que moldam a identidade.

Neste artigo, analisamos o discurso autobiográfico de adultos pouco escolarizados, centrando-nos na forma como se apresentam e justificam o seu modo de ser. Olhamos para esse "eu" compreendido reflexivamente pela pessoa em termos da sua autobiografia, ou seja, aquilo a que Giddens (2002) designa de autoidentidade. O nosso objetivo é encontrar os recursos reflexivos que dão conteúdo à autoidentidade e à forma como esta varia social e culturalmente em função da variação das estórias que compõem a história pessoal.

Face ao nosso objetivo recorremos a um conjunto de cem documentos autobiográficos elaborados em processos de Reconhecimento, Validação e Certificação de Competências (RVCC) entre 2006 e 2012. O sistema RVCC, implementado em Portugal em 2001, é uma oferta do sistema educativo destinado ao público adulto que visa o reconhecimento e a validação das aprendizagens que ocorrem ao longo da vida e a consequente atribuição de um certificado de equivalência escolar. Este processo é orientado por Referenciais de Competências-chave onde estão elencadas as competências necessárias para a certificação. O processo é orientado para a elaboração e recolha de informação organizada num documento, designado de Portefólio Reflexivo de Aprendizagens e que assenta num conjunto de pressupostos metodológicos: o Balanço de Competências e a abordagem Autobiográfica. É através dos materiais que o adulto produz e que colige, de forma contextualizada e crítica, que os formadores validam as competências possuídas pelo adulto, para, num momento posterior, serem objeto de certificação formal.

\section{Metodologia}

O material autobiográfico foi recolhido em quatro escolas da região Alentejo e refere-se a candidatos que concluíram o processo RVCC entre 2006 e 2012. Apesar de não ter existido a preocupação em constituir uma amostra estatisticamente representativa de autobiografias, procurouse diversifica-la, ajustando-a, na medida do possível, ao perfil dos 1400 candidatos certificados à 
data de setembro de 2012. Na tabela 1 é apresentada a distribuição da amostra pelas diferentes variáveis de caraterização.

Tabela 1 - Caracterização da amostra

\begin{tabular}{|c|c|}
\hline & $N$. \\
\hline \multicolumn{2}{|l|}{ Sexo } \\
\hline Masculino & 45 \\
\hline Feminino & 55 \\
\hline \multicolumn{2}{|l|}{ Grupo etário } \\
\hline$>64$ anos & 5 \\
\hline Entre 55 e 64 anos & 10 \\
\hline Entre 45 e 54 anos & 35 \\
\hline Entre 35 e 44 anos & 30 \\
\hline Entre 25 e 34 anos & 18 \\
\hline$<25$ anos & 2 \\
\hline \multicolumn{2}{|l|}{ Habilitações literárias } \\
\hline $1 .^{\circ}$ ciclo (4 anos de educação formal) & 31 \\
\hline $2 .^{\circ}$ ciclo (6 anos de educação formal) & 60 \\
\hline $3 .^{\circ}$ ciclo ( 9 anos de educação formal) & 9 \\
\hline
\end{tabular}

O material autobiográfico recolhido foi compilado e trabalhado de modo a sujeitá-lo aos procedimentos de análise de conteúdo seguindo a lógica subjacente à análise qualitativa (GUERRA, 2008), com o propósito de interpretar e reconstruir o sentido da narrativa. Subjaz ao trabalho analítico a ideia de que os conteúdos narrativos indiciam conteúdos culturais latentes que são mediados pelas estruturas sociais e simbólicas que contextualizam a sua produção (RUQUOY, 1997).

Num primeiro momento, procedeu-se à determinação de categorias analíticas e à construção de uma grelha de análise. Num segundo momento, identificou-se, nos documentos autobiográficos, as unidades de registo categorizáveis e análogas entre si. As unidades de registo identificadas foram, sobretudo, de natureza semântica (baseadas numa escolha resultante do sentido temático) e linguística (destacando-se, a este nível, as palavras-chave) (GHIGLIONE; MATALON, 2001). Todo o corpus analítico foi classificado com base nos critérios seguidos na análise de conteúdo (BARDIN, 2009): a exaustividade (abrangendo a totalidade do material recolhido), a 
exclusividade (evitando classificar um mesmo elemento do conteúdo em duas categorias diferentes) e a pertinência (procurando classificar os trechos em função dos objetivos da análise).

\section{A APRESENTAÇÃO DE SI COMO O RESULTADO DO PROCESSO DE SOCIALIZAÇÃo}

O sistema RVCC assenta na ideia de que os indivíduos se formam ao longo da vida, num processo de progressiva construção do eu baseada na reflexividade que deriva das escolhas e das responsabilidades individuais. A apresentação de si na narrativa autobiográfica, solicitada ao longo do processo RVCC, conduz à elaboração de descrições sobre o processo de incorporação do social a partir dos diferentes contextos que os sujeitos integraram, entre os quais se destaca o período da infância. De facto, muitos dos relatos autobiográficos tendem a relevar a importância de situações vividas na infância no processo de formação de si. Nestes casos, os sujeitos apresentam-se como o resultado da identificação com um outro significativo que, na maioria das vezes, se trata de um familiar. O vínculo afetivo com esse sujeito é fortemente enfatizado na autobiografia:

Tenho muitas recordações, nomeadamente: - Os tempos de fim-de-semana e férias, que passava com o meu avô materno no campo [...] Ensinou-me que é preciso pouco para ser feliz, gostava da forma como ele encarava a vida, sempre com um sorriso nos lábios. (Cesário, 32 anos)

A descrição da relação com os "outros significativos", com quem se aprendeu na infância, constituem elementos da narrativa autobiográfica onde se identificam aprendizagens de vida. As marcas destes processos, ainda que situados na infância, perpetuam-se indefinidamente na definição do caráter individual dos sujeitos, alicerçando a autenticidade de si. A apresentação de si incursa pela identidade individualizada, nos moldes descritos por Taylor (1997), conjugada com o ideal de ser fiel a si próprio, ao seu modo de ser. É no plano da intimidade que decorrem as aprendizagens que moldam o caráter individual, constituindo uma dimensão onde a identidade é particularmente vulnerável ao reconhecimento conferido pelos "outros significativos". Estes relacionamentos desencadeiam, na esfera da intimidade, processos de autodescoberta e de autoafirmação (TAYLOR, 1997, p. 36) que assumem destaque nas autobiografias por constituírem importantes referências identitárias:

A minha mãe tinha-me dado as redes para pescar. [...] A minha mãe ensinou-nos esses valores, respeitar os outros, ser humilde, ajudar quem precisa, dar uma palavra de conforto ao outro, repartir o que temos. (Carla, 61 anos).

Nesta dimensão da narrativa autobiográfica, a apresentação de si perde um sentido mais monológico da autorrealização de si, ganhando um sentido mais dialógico. Como refere Taylor (1997, p. 33), a identidade é definida em diálogo com um “outro significativo”, mesmo após o seu 
desaparecimento. A identidade, na perspetiva deste autor, é formulada em diálogo com aquilo que os outros significativos desejam ver deles. A relação entre a genuinidade da identidade e o reconhecimento na esfera da intimidade resulta, assim, da relação estabelecida com o outro significativo. É a partir do trabalho de Mead que Taylor desenvolve o conceito de outro significativo, em particular na alusão ao processo pelo qual o indivíduo, em interação com os outros, a eles se assemelha na realização das mesmas coisas (MEAD, 1927, p. 193). A esfera íntima, na qual a identidade é formada e reconhecida em diálogo com os outros, é transposta para o relato autobiográfico, sendo, portanto, na descrição da relação com o outro que se sustenta, em parte, a validação de si.

Os sujeitos fazem, através da narrativa, uma revisitação da infância e descrevem diferentes episódios de aprendizagens sob o prisma daquilo que são os objetivos do processo RVCC. Os modos de descrição das primeiras aprendizagens variam, no entanto, em função dos diferentes modos de reconhecimento da individualidade que conheceram na infância. Como refere Taylor (1997, p. 36-37), as condições de reconhecimento da individualidade estão associadas à confiança que se adquire nas relações de intimidade desde a infância. Na mesma linha, Honneth (2011, p. 131) refere-se ao amor como a forma mais básica de reconhecimento, isto é, na experiência recíproca de uma dedicação amorosa os sujeitos sabem-se unidos na dependência mútua ao nível da necessidade. Neste sentido, o amor dos adultos constitui um elemento fundamental para que a criança se torne num indivíduo autónomo e comunicativo. As relações de reconhecimento baseadas no amor preparam "o caminho para um tipo de auto-relacionamento em que os sujeitos alcançam reciprocamente uma confiança elementar em si próprios, ela precede qualquer outra forma do reconhecimento recíproco" (HONNETH, 2011, p. 146). Na narrativa autobiográfica o amor assume grande relevância na descrição da infância:

Tive uma infância feliz na medida do possível, nunca me faltou o amor e o carinho dos meus pais e dos meus irmãos. (Teresa, 34 anos)

O amor na esfera íntima inscreve-se, ele próprio, no processo de aprendizagem e de formação do caráter individual. Como refere Abrantes (2013), as memórias da infância encontramse marcadas por laços sentimentais estabelecidos com outros, apresentados como decisivos para as competências, identidades e valores desenvolvidos. A vertente emocional do processo de socialização é observável nas descrições de definição do eu:

Com os meus pais aprendi a ser educada, trabalhadora, sociável, a respeitar os outros, a ser respeitada, a partilhar com todos, dar muito amor e carinho e também aprendi a rir e a chorar. (Guilhermina, 46 anos) 
Nos relatos dos sujeitos que viveram dificuldades financeiras, o amor na esfera íntima constitui uma compensação face às dificuldades sentidas:

Os meus pais viveram sempre com dificuldades, mas criaram os 3 filhos com muito amor e carinho e nunca passámos fome, graças a Deus. (Gabriela, 38 anos)

É entre os vínculos afetivos de natureza positiva mas também de natureza negativa, determinantes na vivência da infância, que se encontram diferentes formas de narração do processo de reconhecimento nesse período. Axel Honneth define a violação da integridade corporal como a negação ou supressão de reconhecimento através do amor. De acordo com o autor, "os maus-tratos físicos de um sujeito apresentam um tipo de desrespeito que lesa duradouramente a confiança aprendida através do amor [...] uma ruptura dramática da confiança na solidez do mundo social e, por conseguinte da própria auto-segurança" (HONNETH, 2011, p. 181). A quebra de confiança associa-se, assim, na perspetiva de Honneth, à violação da integridade física. Por sua vez, David Owen (2007) alarga-a a outras situações em que se abalam as componentes básicas de confiança que estruturam a experiência de si. Owen (2007, p. 308) dá como exemplos a experiência de catástrofes naturais, a experiência de ser agredido por estranhos ou a experiência de acontecimentos inesperados e traumatizantes. Em todos estes casos reside um potencial de quebra da manutenção dos modos mais básicos de autoconfiança. A narrativa autobiográfica dá conta destas quebras, nos casos em que ocorrem, e das suas consequências, que ressoam na forma como os sujeitos se perspetivam. No entanto, olhando em perspetiva e de forma distanciada, os sujeitos tendem a apresentar essas situações como ruturas biográficas de que resulta a aprendizagem daquilo que é a vida. A maioria das situações diz respeito à perda de um dos progenitores na infância, o que, nestes casos, significa a constatação precoce da vulnerabilidade relativamente aos acontecimentos de vida e a experiência da impotência relativamente ao rumo dos acontecimentos:

[...] infelizmente com 9 anos tive o primeiro desgosto da minha vida. A minha mãe faleceu devido a uma grave doença no fígado e a família feliz que éramos desabou. [...] Enfim, comecei a aprender que a vida não é um mar de rosas, temos que aprender a sobreviver por mais dificeis que sejam os espinhos que encontramos. (Berta, 54 anos)

A revisitação, na narrativa, dos episódios infelizes vividos na infância constitui uma marca do amadurecimento precoce, são apresentados como momentos de aprendizagem que moldam a estrutura do caráter individual. A perda de um dos progenitores constitui um ponto de bifurcação da história de vida do qual resulta a determinação de quem se é entre os diferentes “eus" possíveis. Estes são acontecimentos decisivos com consequências particulares para os indivíduos e que, como refere Giddens (2002, p. 107), “podem ser entendidos como os traços mais amplos [...] que um indivíduo leva consigo na vida cotidiana e no curso de sua existência”. A consequência imediata 
destes acontecimentos é um abalo na segurança ontológica vivida no período da infância ou juventude. Contudo, são descritas na narrativa outras repercussões, de longo prazo, que correspondem, nas palavras dos sujeitos, à alteração do curso previsível da vida. A este propósito, o relato de Gabriela é ilustrativo na forma como, em retrospetiva, encara o falecimento da mãe, simultaneamente como uma alteração do "curso" da vida e um episódio de crescimento individual:

Hoje avalio o facto como um crescimento prematuro, e à força, pois se a minha mãe não me tivesse faltado, a minha vida tinha sido muito diferente da que estou a contar agora. (Gabriela, 38 anos)

Pelos exemplos anteriormente apresentados, percebemos que a infância constitui um eixo importante da narrativa autobiográfica. É através dos episódios de infância e no modo como se produz a vivência dessa fase da vida que se apresentam as bases de quem se é. A amplitude geracional do sistema RVCC propicia, no entanto, a existência de relatos que diferem em função das condições de vivência da infância, que variam, normalmente, com a idade do sujeito. No material autobiográfico analisado, as diferenças sobressaem, especialmente, em relação às condições de vivência da infância produzidas em diferentes épocas. A infância e adolescência, por exemplo, não se afirmavam como etapas autónomas noutros tempos (MEAD,1927; CORSARO, 2005). Entre os candidatos mais velhos destaca-se a dureza das condições de vida de então em comparação com as condições atuais. O contraste geracional que encontramos no discurso relativamente às condições de vivência da infância é marcado pela existência de infraestruturas coletivas (MARTUCCELLI, 2006), viabilizadas pelo modelo de estado social que se procurou implementar em Portugal a partir de meados da década de setenta. A forma como os diferentes amortecedores sociais se configuram em determinado contexto social é decisiva para o processo de individuação (MARTUCCELLI, 2006). No caso concreto das infraestruturas coletivas, estas constituem amortecedores das desigualdades sociais e são potenciadoras de sociedades mais igualitárias. Os candidatos mais novos beneficiaram de um conjunto de recursos garantidos, direta ou indiretamente, pelo estado e que, apesar de tudo, permite um nivelamento mínimo dos modos de vida e experiências sociais da infância. Assim, se o processo de individuação dos candidatos mais velhos é configurado pelos desafios levantados em circunstâncias profundamente desiguais, no caso dos candidatos mais novos esse processo beneficia de recursos e de infraestruturas promotoras de maior igualdade social.

O fator geracional é, desta forma, um elemento diferenciador dos modos de descrição das aprendizagens precoces na narrativa autobiográfica. Mesmo a conceção de adolescência é utilizada de diferentes modos como recurso narrativo na produção da imagem de si. Entre os candidatos mais 
velhos, a adolescência é encurtada numa transição entre a infância e a adultez, marcada pelo início precoce da vida profissional.

A minha adolescência não foi senão uma sequência lógica da infância no sentido em que a dureza da vida, de um modo geral, não acabou. [...] a minha vida profissional começou aos 11 anos de idade. Como é de calcular, o trabalho na construção civil para uma criança desta idade não era nada fácil, mas porque os recursos da família eram escassos, não restava outra alternativa. (Anacleto, 71 anos).

Entre os candidatos mais novos a adolescência tende a ser encarada como um período relativamente mais prolongado, pela experiência escolar, entre o mundo da infância e o mundo da idade adulta. A indefinição do estatuto de adolescência, entre o estado inicial da infância e o estado final, e idealmente acabado, da adultez permite utilizar a instabilidade desse período como uma forma de desculpabilização para os "erros" cometidos e apenas percebidos posteriormente:

Voltando ao meu percurso escolar, fui passando ano a ano, nunca com notas extremamente altas, mas o suficiente para nunca reprovar, mas quando frequentava o $9^{\circ}$ ano, pelos meus 16 anos na fase "dificil" da adolescência, gostava muito de dar umas faltinhas para frequentar o Salão de jogos (Máquinas Arcade), onde passei algum tempo em demasia, tanto que acabaria assim por reprovar a minha primeira vez. (Francisco, 28 anos).

Em suma, os sujeitos tendem a explicar o desenvolvimento das primeiras competências com base nas relações interpessoais que ocorreram no contexto familiar durante a sua infância. É aí que estabelecem as bases do caráter e que reside o surgimento de si que se desenvolve na narrativa. A importância da família, em particular dos pais, no processo de socialização é amplamente realçada nas narrativas autobiográficas analisadas. Os valores aprendidos com os pais são apresentados como fundamentais na construção biográfica do eu.

\section{A APRESENTAÇÃo de SI ENQUANTO REFLEXO dOS PAPÉIS SOCIAIS}

Os papéis sociais constituem um segundo recurso de apresentação de si na narrativa autobiográfica. Sobressai, neste particular, a forma como a argumentação obedece a lógicas de construção social de identidades de género que veiculam papéis sociais específicos. As diferenças de género na construção identitária revelam-se na forma como as mulheres tendem a centrar as descrições nas responsabilidades domésticas e familiares, ao passo que os homens valorizam a participação comunitária e as práticas de lazer. Estas tendências parecem contrastar com os processos de destradicionalização que têm modificado os pressupostos da "modernidade organizada" (WAGNER, 2002), daí resultando a pluralização e flexibilização das biografias individuais. Kaufmann (2003) salienta, contudo, que a individualização é um produto do social, pelo que os indivíduos não se emanciparam dos quadros da tradição movidos, exclusivamente, por 
vontade própria. Certo é que os contextos históricos e institucionais de maior flexibilização e mais plurais parecem complexificar as vidas individuais. É, sobretudo, na esfera do trabalho que são referenciados profundos impactos dessa flexibilização na instabilização dos percursos profissionais. No entanto, como refere Aboim (2010, p. 111), é no âmago da vida privada que, no presente, a destandardização parece adquirir contornos mais assinaláveis e espetaculares. Como adianta Almeida (2011, p. 10), "confrontados com quadros de socialização heterogéneos (a família, a escola, os media, os grupos de pares), por vezes até concorrentes ou contraditórios entre si, os portugueses vivem a sua vida privada cada vez mais sob o signo da pluralidade”. Martuccelli (2006, p. 159) assinala a forma como atualmente a família coloca o indivíduo numa tensão entre as obrigações morais e as lealdades éticas. Segundo o autor, a família continua a ser um lugar onde a tradição tem um peso significativo, mas hoje tornou-se, igualmente, num lugar de liberdade onde cada um vive a sua vida sem se descomprometer da vida em comum: todos os membros da família são uns com os outros sem deixar de ser eles mesmo (MARTUCCELLI, 2006, p. 206). Apesar de subsistirem conceções mais ou menos partilhadas dos papéis sociais, ainda regulados por normas informais e expetativas socialmente partilhadas, regista-se um enfraquecimento da regulação institucional da vida. Como refere Beck (1992, p. 89), a espiral da individualização ocorre, também, no interior da família: as famílias tornam-se num palco de malabarismos contínuos de múltiplas ambições divergentes entre as necessidades profissionais, os deveres parentais e a monotonia do trabalho doméstico. A narrativa dos sujeitos dá conta dessa tendência de "negociação" das relações familiares, de cariz mais igualitário, que coexiste, ainda assim, com vários exemplos de relatos que não constituem uma rutura efetiva com representações e práticas assentes em desigualdades de género.

Nas narrativas femininas, o papel de "dona de casa" constitui um importante repositório de descrição de competências, dada a amplitude de funções que lhe são atribuídas. A larga abrangência das tarefas socialmente atribuídas permite às candidatas evidenciar competências tão díspares como as relacionadas com a gestão de orçamentos (caso de Dalila) ou as relacionadas com a utilização de tecnologias (caso de Palmira):

Em relação às minhas tarefas como dona de casa, posso dizer que sou eu que comando o lar. Costumo fazer o orçamento familiar e quando chega ao fim do mês costumo fazer contas pois tenho que pagar a luz, a água, o telefone, toda a alimentação e gerir o dinheiro para o resto do mês. (Dalila, 49 anos)

Como dona de casa, embora tenha mais tempo para realizar algumas tarefas, não deixo de utilizar (e não consigo passar sem eles) alguns equipamentos tecnológicos que são uma mais-valia, como por exemplo a máquina de lavar a roupa, a máquina de lavar a loiça que me deixam mais tempo para os meus hobbies. (Palmira, 61 anos). 
Sobressai, no relato das candidatas, a normatividade dos papéis sociais assumidos que apontam para a existência de formas de estandardização simbólica da importância das responsabilidades socialmente atribuídas como elementos de aprendizagem. Assim, à ideia de uma efetiva despadronização e deslenialização das biografias individuais, contrapõe-se, como nota Aboim (2010), a persistência de elevados níveis de estandardização normativa. O manancial de prescrições, proscrições e permissões associadas aos diferentes papéis sociais constitui um repositório de descrição de competências desenvolvidas ao longo daquilo a que Setterstein designa de tempo da família: i.e., a modificação de identidades, responsabilidades e relacionamentos que ocorre à medida que os indivíduos alteram a sua posição geracional na estrutura familiar (SETTERSTEIN, 2002, p. 22). No discurso das candidatas, a constituição de família, a experiência da maternidade e as responsabilidades domésticas são aspetos valorizados na construção de um eu distintivo que adquire, por via dessas experiências, novas competências. A experiência da maternidade marca, em particular e de forma vincada, a narrativa das candidatas que são mães. $\mathrm{O}$ nascimento dos filhos é descrito como um processo de mudança radical na vida, de onde resultam novas aprendizagens:

Fui mãe aos 31 anos e a minha vida mudou. As responsabilidades aumentaram, a minha vida passou a girar à sua volta. Tive de aprender a gerir melhor o dinheiro, pois as contas eram mais elevadas. Tive de aprender a tratar de uma criança e a perceber o que ela precisava. (Guilhermina, 46 anos)

As relações de intimidade são, igualmente, palco de aprendizagens. A este nível, destaca-se o processo de aprendizagem da convivência conjugal. A superação ou minoração de conflitos no quotidiano conjugal constitui evidência da aquisição de competências relacionais:

Com o meu marido, no princípio do casamento tínhamos muitas discussões, mas depois tudo se resolveu ao longo do tempo e agora está tudo mais razoável. Mas obviamente sempre aprendi muitas coisas com ele (Belarmina, 39 anos).

O amadurecimento resultante da adaptação aos papéis sociais promove a imagem de si como o produto do curso de vida, marcado por ruturas e descontinuidades, mas que é, simultaneamente, um processo de desenvolvimento pessoal que assume uma dimensão sequencializada, normativa e organizada. A descrição pormenorizada do desempenho de diferentes papéis permite, às candidatas, ancorar a argumentação em imagens institucionalizadas e legitimadas socialmente. Nesse sentido, a própria condição de mulher, que concilia, de forma articulada, uma pluralidade de papéis sociais, constitui per si um elemento destacado e valorizado na narrativa:

O meu papel de mãe, esposa, dona de casa e cozinheira por conta própria foi difícil, apesar de revelar como as mulheres têm conquistado o seu espaço ao longo dos tempos, na nossa história. As mulheres emanciparam-se, entraram no mundo do trabalho, passaram a votar e participam no mundo da política. (Ângela, 51 anos). 
A narrativa dos homens tende a ser conduzida por orientações normativas distintas daquelas que caracterizam o discurso das mulheres. A vida doméstica perde a relevância, assim como a centralidade que ocupa no discurso feminino, sendo substituída pela valorização da vida pública, nomeadamente a participação em atividades associativas, políticas ou de lazer. As narrativas autobiográficas encerram, assim, indícios de um modelo de masculinidade onde a identidade está fortemente vinculada aos papéis da esfera pública. No caso dos candidatos que detêm cargos de direção em associações, a descrição do desempenho das suas responsabilidades e funções é particularmente ilustrativo da relevância atribuída à esfera pública. As descrições enfatizam a aprendizagem de competências nos contextos associativos, podendo até transpor este domínio e estender-se a outros contextos, como a saúde ou o ambiente. A cooperação e a partilha são destacadas como elementos da vida associativa que potenciam aprendizagens:

Através de uma associação de caçadores à qual pertenço e através da convivência que temos todos os sócios, sempre aprendemos alguma coisa, seja em maneiras diferentes de praticar a caça ou de novos métodos ou do estado das espécies. (César, 42 anos)

À semelhança do que se verifica no discurso das mulheres, na narrativa dos sujeitos de sexo masculino a condição masculina é, em si mesma, um estado revelador de competências que lhes são próprias. Aspetos como a disciplina, a autonomia ou o espírito de sacrifício constituem características que se revelam nas descrições de atividades realizadas em contextos tipicamente associados à masculinidade. Verificamos um investimento particular nesses relatos que constituem marcas de caráter e motivo de orgulho individual, contribuindo, de forma significativa, para o embelezamento de si. O cumprimento do serviço militar, universo outrora exclusivo dos homens, constitui um exemplo típico desses relatos. Aprender a ser homem é uma dimensão importante do discurso de apresentação de si. Trata-se de um processo de aprendizagem, na "escola de vida", que vai ao limite "inacreditável" do sofrimento humano (nas palavras de Daniel), mas que simultaneamente, como refere Fausto, permite o contacto com tarefas domésticas a que não estava habituado, como fazer a cama:

Sempre ouvi dizer que a tropa não fazia mal a ninguém, pelo contrário, só fazia bem. Só após o cumprimento do serviço militar é que compreendi o significado destas palavras, pois no desempenho do serviço militar têm que se efectuar tarefas que, muitas vezes, não estamos habituados a fazer em casa, tais como, fazer a cama, cumprir a rigorosa pontualidade para tudo e obedecer às regras estipuladas. A obrigatoriedade do desempenho destas funções impõe hábitos e princípios de responsabilidade que se adquirem para o resto da vida. (Fausto, 40 anos).

Como observamos, pelos exemplos apresentados, no caso dos sujeitos de sexo masculino, a invocação, na narrativa, do desempenho de papéis sociais como prova da detenção de competências é orientada para a esfera pública. No entanto, a esfera privada não fica omissa na 
narrativa. O papel de pai, por exemplo, assume uma dimensão importante da identidade masculina, constituindo uma oportunidade para os sujeitos se considerarem "mais homens" (nas palavras de Bento), adultos e provedores, valorizando, simultaneamente, o seu perfil enquanto candidatos à certificação:

O crescimento do meu filho foi algo de intenso que aconteceu na minha vida e tudo isso era partilhado com a minha mulher. Foi algo que me fez amadurecer ainda mais, tornarme mais homem à medida que tinha que tomar certas decisões. (Bento, 46 anos).

Do ponto de vista das orientações normativas, encontramos refletido no discurso dos candidatos um modelo de casal aliança, ainda centrado na concepção do homem como provedor, mas já modificado pela maior democratização das relações no interior da família (ABOIM, 2010) e pelo apelo a uma matriz de família de organização mais igualitária e paritária comtemplada nos Referenciais. A narrativa molda-se a um modelo de masculinidade menos tradicional e que institui um novo papel masculino, mais participante e afetivo, no seio da vida privada (WALL; ABOIM; MARINHO, 2007). A inclusão na narrativa de descrições de companheirismo e de igualdade não afasta, no entanto, traços do modelo tradicional de provedor e de figura de autoridade. No relato da realização das tarefas domésticas, os sujeitos de sexo masculino limitam-se, invariavelmente, a um papel de ajudante e de colaborador da mulher:

Ajudo a minha esposa nas lides domésticas, como dar banho ao meu filhote, pôr a mesa, arrumar a cozinha, colocar a máquina da roupa ou da louça a lavar e, por vezes, ir às compras. (Zacarias, 34 anos)

Em suma, a narrativa autobiográfica dos candidatos, independentemente do sexo, faz sucessivas alusões aos momentos de transição de vida, os quais constituem um importante recurso narrativo no processo de apresentação de si. A descrição destes momentos ancora ideais e prescrições sociais que traduzem uma normatização argumentativa que coexiste na narrativa com o discurso de individualização e autodesenvolvimento.

\section{CONCLUSÃo}

A análise realizada permitiu identificar dois recursos distintos, ainda que complementares, de apresentação autobiográfica de si. Um primeiro recurso corresponde à descrição da forma como o sujeito se tornou ele próprio. Estas descrições estão vinculadas às experiências de infância que moldaram o caráter individual do sujeito. $\mathrm{Na}$ generalidade dos relatos analisados, as relações familiares que se tecem na esfera privada constituíram a fonte dos valores individuais dos sujeitos e o molde da sua forma de ser. A aprendizagem na infância constitui, deste modo, uma dimensão 
importante das narrativas autobiográficas. A descrição de imagens e lembranças do passado procura justificar a orientação do processo de se tornar quem se é.

O segundo recurso narrativo na apresentação de si é a descrição de aprendizagens e de competências que decorrem dos diferentes papéis sociais assumidos. As transições de vida assumem particular destaque na autobiografia. As cronologias da vida privada, em particular a conjugalidade e a parentalidade, constituem momentos chave de aprendizagem. As narrativas sustentam-se, assim, em conceções da figura de parceiro e/ou de progenitor construídas a partir do relato das experiências quotidianas, daí resultando evidências do desenvolvimento de competências sociais. Nesta dimensão destaca-se, a forma como as diferenças de género se repercutem na natureza da argumentação.

Como se constata, os alicerces da autoidentidade variam em função dos contextos de origem dos sujeitos. Cada autobiografia integra elementos do mundo exterior que constituem importantes recursos na explicação de si mesmo. De acordo com Lalanda (1998): "contar-se é também olhar-se e identificar momentos marcantes de transição e mudança”, as narrativas autobiográficas analisadas demostram isso mesmo. O eu que é descrito nas narrativas assume a forma do projeto reflexivo a que alude Giddens (2002). Trata-se de um eu alterado por momentos de transição e cuja construção e coerência se baseia na invocação dos valores adquiridos na infância e nos diferentes papéis sociais que o sujeito assume.

\section{REFERENCIAS}

ABOIM, S. Conjugalidades no Masculino: Renegociando Poderes e Identidades no Quotidiano. In: WALL, K.; ABOIM, S.; CUNHA, V. (ed.) A vida Familiar no Masculino: Negociando Velhas e Novas Masculinidades. Lisboa: Comissão para a Igualdade no Trabalho e no Emprego, 2010. p. 159-223.

ABRANTES, P. A escola da vida: socialização e biografia(s) da classe trabalhadora. Lisboa: Mundos Sociais, 2013.

ALMEIDA, A. Os nossos dias. In: MATTOSO, J. (Dir.), História da vida privada em Portugal (4 Vol). Lisboa: Círculo de Leitores / Temas e Debates, 2011.

BARDIN, L. Análise de conteúdo. Lisboa: Edições 70, 2009.

BECK, U. Risk society: towards a new modernity. Londres: Sage Publications, 1992.

BECK, U.; BECK-GERNSHEIM, E. Individualization. Londres: Sage, 2002.

CARVALHO, I. Biografia, identidade e narrativa: elementos para uma análise hermenêutica.

Horizontes antropológicos, v. 9, n. 19, p. 283-302, 2003. 
CORSARO, W. The Sociology of Childhood. Thousand Oaks: Pine Forge Press, 2005.

GERGEN, K. The saturated self. Nova Iorque: Basic Books, 1991.

GHIGLIONE, R.; MATALON, B. O Inquérito. Lisboa: Celta Editora, 2001.

GIDDENS, A. Modernidade e identidade. Rio de Janeiro: Zahar, 2002.

GUERRA, I. Pesquisa qualitativa e análise de conteúdo: sentidos e formas de uso. Lisboa: Principia, 2008.

HALL, S. A identidade Cultural na Pós-modernidade. Rio de Janeiro: DP\&A, 1998.

HONNETH, A. Luta pelo Reconhecimento - para uma gramática moral dos conflitos sociais. Lisboa: Edições 70, 2011.

KAUFMANN, J. Ego: para uma sociologia do indivíduo. Lisboa: Instituto Piaget, 2003.

KAUFMANN, J. A Invenção de Si: uma teoria da identidade. Lisboa: Instituto Piaget, 2005.

LALANDA, P. Sobre a metodologia qualitativa na pesquisa sociológica. Análise Social, v. 33, n. 148, p. 871-883, 1998.

MAHEIRIE, K. Constituição do sujeito, subjetividade e identidade. Interações, v. 7, n. 13, p. 31-44, 2002.

MARTUCCELLI, D. Forgé par l'épreuve: l'individu dans la France contemporaine. Paris: Armand Collin, 2006.

MEAD, M. Coming of Age in Samoa. Nova Iorque: Blue Ribbon Books, 1927.

RASERA, E.; GUANAES, C.; JAPUR, M. Psicologia, ciência e construcionismos: dando sentido ao self. Psicologia: Reflexão e Crítica, v. 17, n. 2, p. 157-165, 2004.

RUQUOY, D. Situação de entrevista e estratégia do entrevistador. In: AA.VV., Práticas e Métodos de Investigação em Ciências Sociais. Lisboa: Gradiva, 1997.

SETTERSTEN, R. New Frontiers in Socialization. London: Elsevier Science, 2002.

TAYLOR, C. The politics of recognition. In: HEBLE, A.; PENNE, P.; STRUHERS, J. (ed.), New contexts of Canadian criticism. Peterborough: Broadview Press, 1997. p. 98-131.

OWEN, D. Self-government and 'democracy as reflexive co-operation: Reflections on Honneth's social and political ideal. In: BRINK B.; OWEN, D. (ed.) Recognition and power: Axel Honneth and the tradition of critical social theory. Cambridge: University Press, 2007. p. 290-320.

WAGNER, P. A sociology of modernity: liberty and discipline. Londres: Routledge, 2002.

WALL, K.; ABOIM, S.; MARINHO, S. Fatherhood, family and work in men's lives: negotiating new and old masculinities. Recherches Sociologiques et Anthropologiques, v. 38, n. 2, p. 105-122, 2007. 